\title{
EDITORIAL
}

\section{Oestrogen and the sexual dimorphism of pulmonary arterial hypertension: a translational challenge}

\author{
Jessica K. Paulus*,\# and Kari E. Roberts
}

$\mathbf{T}$ he striking female predominance in idiopathic and familial pulmonary arterial hypertension (PAH) has been well documented since the publication of the National Institutes of Health (NIH) registry in 1987 [1]. In the majority of PAH registries, females are at least twice as likely to be represented as males, with female to male ratios as high as four to one [2-6]. Notably, these sex differences are not fully explained by a differential distribution of known risk factors for PAH by sex, such as autoimmune disease or anorexigen exposure. Taken together, these epidemiological data suggest that other sex-associated factors, including sex hormones, may influence PAH pathogenesis.

Endogenous and exogenous sex hormone exposures represent a biologically plausible potential risk factor for PAH. Sex hormones determine in utero organ development, drive tissuespecific changes in early life and exert an evolving influence across the life span as their absolute and relative concentrations shift [7]. There can be no doubt that sex hormones, with their ability to modulate vascular tone, inflammation and remodelling, play a fundamental role in determining cardiovascular phenotypes [8]. Emerging data on the importance of sex hormones in animal models of pulmonary hypertension provide tantalising evidence that the pulmonary vascular phenotype of an organism is dependent upon these pleiotropic signalling molecules $[9,10]$.

In this issue of the European Respiratory Journal, YUAN et al. [11] demonstrate that monocrotaline (MCT) creates an oestrogendeficient state in rats characterised by low plasma oestradiol (E2) and altered pulmonary expression of oestrogen receptors and enzymes responsible for E2 anabolism (reduced) and catabolism (increased). In the absence of sufficient endogenous (i.e. postovariectomy) or exogenous oestradiol, a pro-proliferative, anti-apoptotic and vasoconstrictive phenotype emerges that is mediated in part via reduced nitric oxide and prostacyclin, and increased endothelin. Rescue of the phenotype via the provision of exogenous E2 illustrates the homeostatic influence of oestrogen signalling on the pulmonary circulation of these animals. These

${ }^{*}$ Tufts Clinical and Translational Science Institute, Tufts University, Boston, MA, ${ }^{*}$ Dept of Epidemiology, Harvard School of Public Health, Boston, MA, and "Dept of Medicine, Tufts Medical Center, Boston, MA, USA.

CORRESPONDENCE: K.E. Roberts, Tufts Medical Center, Dept of Medicine, Pulmonary, Critical Care and Sleep Division, 800 Washington Street, \#257, Boston, MA 02111, USA. E-mail: kroberts@tuftsmedicalcenter.org data add depth to a growing body of literature that explores the mechanisms by which oestrogen, as well as its metabolites [12] and receptors [13, 14], protects against pulmonary hypertension in the MCT-exposed rat.

Now we are presented with the challenge of how to translate and apply these findings to our understanding of human PAH. Study of these model systems has provided tremendous insights into the biology of oestrogen signalling in the pulmonary circulation. While this biology is critical to pulmonary vascular phenotypes in both humans and animals, the story of sex in PAH is far from complete. Current animal models can offer only limited insight into sex differences in $\mathrm{PAH}$, due to the "oestrogen paradox" whereby female animals are relatively protected against the incidence of pulmonary vascular remodelling, right ventricular failure and death when challenged with hypoxia or MCT as compared to males [15]. This distinction underscores the importance of investigating determinants of sexual dimorphism in human PAH.

Epidemiological studies of $\mathrm{PAH}$ are challenged by the rarity of the disease, but the few that have been conducted to date suggest that exogenous hormones and reproductive events have a role in PAH. The NIH registry reported that a history of oral contraceptive use was associated with an earlier age of PAH onset (30.9 versus 39.9 years, $\mathrm{p}<0.002)$ [16]. SWEENEY and VoelKel [17] reported high rates of oral contraceptive and hormone replacement therapy use in a cohort of pre- and postmenopausal females with PAH. Though these studies did not include a comparison group of unaffected females, they do suggest that females with PAH may have a different level of exposure to exogenous oestrogens (oral contraceptives and/or hormone replacement therapy) than the general population. There is also clear evidence that pregnancy in PAH is associated with malignant, and potentially fatal, progression of PAH and right ventricle failure [18-20], though it is unknown whether this is attributable to the vascular effects of hormones or to right ventricular decompensation in the face of pregnancyinduced increases in plasma volume and cardiac output. Lastly, among patients with scleroderma, post-menopausal status is a strong predictor of PAH incidence [21] and provision of hormone replacement therapy may attenuate this risk [22].

Emerging data on $\mathrm{PAH}$ prognosis adds more complexity to the question of how sex-related factors influence PAH. While females represent the majority of PAH cases diagnosed, in fact they enjoy a relatively longer survival as compared to their male counterparts. Male sex is a strong predictor of death from 
$\mathrm{PAH}[23,24]$, and its impact is magnified with advancing age [25], raising the interesting possibility that a dynamic hormonal milieu, defined by the relative contributions of male and female sex hormones that change over time, impacts both the pulmonary vessels and right ventricle. Whether this differential survival results from a shift to a more oestrogenic state in male menopause, confounded by prognostically favourable factors more common in females, or differential right ventricular function by sex [26] remains unknown. Alternatively females may derive a greater therapeutic benefit from approved PAH therapies, a hypothesis supported by the recent analysis of endothelin receptor antagonist clinical trials by GABLER et al. [27]. These demonstrations of sexual dimorphism necessitate further investigation into the impact of sex hormones on the pulmonary circulation and the right ventricle's response to increased pulmonary vascular resistance in order to enhance our understanding not only of pathogenesis but also of PAH progression and outcomes.

Inconsistencies in associations between sex and PAH, be they across species, or between disease incidence and progression, may be partly explained by evidence that complex interactions between genetic and environmental determinants govern the course of the disease. In fact, several lines of evidence implicate a sex-gene interaction in $\mathrm{PAH}$ pathogenesis. Female sex increases the penetrance of mutations in bone morphogenetic protein receptor II (BMPR2) in families with heritable $\mathrm{PAH}$, especially after puberty [28]. In human lymphocytes BMPR2 expression is differential by sex, and modulated by oestradiol in an oestrogen receptor-dependent fashion [29]. Penetrance of BMPR2 mutations is modified by polymorphisms in CYP1B1, an oestrogen metabolising enzyme [30]. Furthermore, in the only case-control study of $\mathrm{PAH}$ in patients with advanced liver disease, we have shown that common single nucleotide polymorphisms in aromatase (CYP19A1) and oestrogen receptor- $\alpha$ (ESR1) are associated with higher oestradiol levels and a significant increase in the risk of PAH [31]. These data offer a potential pathogenetic link between sex hormones and human PAH.

Despite this wealth of provocative data in animal models and studies enrolling PAH patients, there has never been a controlled epidemiological study of the role of reproductive events or hormonal exposures in PAH incidence. The rarity of $\mathrm{PAH}$ (15 cases per million) has constrained epidemiological investigations to date, with clinical research largely limited to small trials, case series and disease registries [2-3], approaches that cannot identify factors associated with $\mathrm{PAH}$ incidence [32]. Case-control designs can efficiently be applied to the study of risk factors for rare diseases, but management of PAH in referral centres poses a significant challenge to identifying the appropriate control subjects for these cases [33].

The study of the incidence and progression of rare human diseases is inherently challenged by the tasks of assembling adequate sample sizes and biobanks of affected tissues and identifying valid control populations. Nonetheless, efforts to estimate the association between reproductive and hormonal risk factors and PAH are worthwhile, since such epidemiological evidence could illuminate long-standing questions about the marked sex differences in PAH and motivate novel therapeutic strategies. As has been applied in the study of other rare conditions [34], collaborative studies that pool data and biospecimens from high-quality existing $\mathrm{PAH}$ registries and cohorts may offer a step forward towards this goal.

As we increasingly understand the complexities of sex hormone signalling in animals and models of pulmonary hypertension, we should be reminded to question the generalisability of these model systems to human PAH. Each of the animal models commonly used to study pulmonary hypertension possess unique attributes, but none are considered to be satisfactorily representative of human disease. Thus, it is critical that our study of sex differences in PAH is also approached from investigations of human populations. The discipline of translational science encourages us to frame research as a bidirectional concept, in which the knowledge generated from the bedside or the population can be translated to the benches of laboratory science, and vice versa $[35,36]$. For example, observational epidemiological studies can generate novel designs and hypotheses that can be tested using more tractable experimental approaches in the clinical and basic sciences. It is imperative that we apply these translational philosophies to establish research collaborations across the disciplines investigating PAH sex differences. With such an approach, we will be well positioned to speed closure of the knowledge gap concerning sex and $\mathrm{PAH}$ pathogenesis, and to more expeditiously identify novel therapeutic targets.

\section{STATEMENT OF INTEREST}

Conflict of interest information can be found alongside the online version of this article at www.erj.ersjournals.com

\section{REFERENCES}

1 Rich S, Dantzker DR, Ayres SM, et al. Primary pulmonary hypertension. A national prospective study. Ann Intern Med 1987; 107: 216-223.

2 Humbert M, Sitbon O, Chaouat A, et al. Pulmonary arterial hypertension in France: results from a national registry. Am J Respir Crit Care Med 2006; 173: 1023-1030.

3 Badesch DB, Raskob GE, Elliot CG, et al. Pulmonary arterial hypertension: baseline characteristics from the REVEAL Registry. Chest 2010; 137: 376-387.

4 Zhang R, Dai LZ, Xie WP, et al. Survival of Chinese patients with pulmonary arterial hypertension in the modern treatment era. Chest 2011; 140: 301-309.

5 Ling Y, Johnson MK, Kiely DG, et al. Changing demographics, epidemiology, and survival of incident pulmonary arterial hypertension: results from the pulmonary hypertension registry of the United kingdom and Ireland. Am J Respir Crit Care Med 2012; 186: 790-796.

6 Escribano-Subias P, Blanco I, López-Mesequer M, et al. Survival in pulmonary hypertension in Spain: insights from the Spanish registry. Eur Respir J 2012; 40: 596-603.

7 Vassalle C, Simoncini T, Chedraui P, et al. Why sex matters: the biological mechanisms of cardiovascular disease. Gynecol Endocrinol 2012; 28: 746-751.

8 Mendelsohn ME, Karas RH. The protective effects of estrogen on the cardiovascular system. N Engl J Med 1999; 340: 1801-1811.

9 Lahm T, Albrecht M, Fisher AJ, et al. 17 $\beta$-Estradiol attenuates hypoxic pulmonary hypertension via estrogen receptor-mediated effects. Am J Respir Crit Care Med 2012; 185: 965-980.

10 White K, Dempsie Y, Nilsen M, et al. The serotonin transporter, gender, and $17 \beta$ oestradiol in the development of pulmonary arterial hypertension. Cardiovasc Res 2011; 90: 373-382. 
11 Yuan $\mathrm{P}, \mathrm{Wu}$ WH, Gao L, et al. Oestradiol ameliorates monocrotaline pulmonary hypertension via NO, prostaglandin and endothelin-1 pathways. Eur Respir J 2013; 41: 1116-1125.

12 Tofovic SP, Zhang $\mathrm{X}$, Zhu $\mathrm{H}$, et al. 2-Ethoxyestradiol is antimitogenic and attenuates monocrotaline-induced pulmonary hypertension and vascular remodeling. Vascul Pharmacol 2008; 48: 174-183.

13 Nishida M, Hasegawa Y, Tanida I, et al. Preventive effects of raloxifene, a selective estrogen receptor modulator, on monocrotalineinduced pulmonary hypertension in intact and ovariectomized female rats. Eur J Pharmacol 2009; 614: 70-76.

14 Umar S, Iorga A, Matori $\mathrm{H}$, et al. Estrogen rescues preexisting severe pulmonary hypertension in rats. Am J Respir Crit Care Med 2011; 184: 715-723.

15 Umar S, Rabinovitch M, Eghbali M. Estrogen paradox in pulmonary hypertension: current controversies and future perspectives. Am J Respir Crit Care Med 2012; 186: 125-131.

16 D'Alonzo GE, Barst RJ, Ayres SM, et al. Survival in patients with primary pulmonary hypertension. Results from a national prospective registry. Ann Intern Med 1991; 115: 343-349.

17 Sweeney L, Voelkel NF. Estrogen exposure, obesity and thyroid disease in women with severe pulmonary hypertension. Eur J Med Res 2009; 14: 433-442.

18 Jaïs X, Olsson KM, Barbera JA, et al. Pregnancy outcomes in pulmonary arterial hypertension in the modern management era. Eur Respir J 2012; 40: 881-885.

19 Duarte AG, Thomas S, Safdar Z, et al. Management of pulmonary arterial hypertension during pregnancy: a retrospective, multicenter experience. Chest 2013 [in press DOI: 10.1378/chest.120528].

20 Katsuragi S, Yamanaka K, Neki R, et al. Maternal outcome in pregnancy complicated with pulmonary arterial hypertension. Circ J 2012; 76: 2249-2254.

21 Scorza R, Caronni M, Bazzi S, et al. Post-menopause is the main risk factor for developing isolated pulmonary hypertension in systemic sclerosis. Ann N Y Acad Sci 2002; 966: 238-246.

22 Beretta L, Caronni M, Origgi L, et al. Hormone replacement therapy may prevent the development of isolated pulmonary hypertension in patients with systemic sclerosis and limited cutaneous involvement. Scand J Rheumatol 2006; 35: 468-471.

23 Humbert $M$, Sitbon $O$, Yaïci A, et al. Survival in incident and prevalent cohorts of patients with pulmonary arterial hypertension. Eur Respir J 2010; 36: 549-555.
24 Lee WT, Ling Y, Sheares KK, et al. Predicting survival in pulmonary arterial hypertension in the UK. Eur Respir J 2012; 40: 604-611.

25 Benza RL, Miller DP, Gomberg-Maitland M, et al. Predicting survival in pulmonary arterial hypertension: insights from the Registry to Evaluate Early and Long-Term Pulmonary Arterial Hypertension Disease Management (REVEAL). Circulation 2010; 122: $164-172$

26 Ventetuolo CE, Ouyang P, Bluemka DA, et al. Sex hormones are associated with right ventricular structure and function: the MESA-right ventricle study. Am J Respir Crit Care Med 2011; 183: 659-667.

27 Gabler NB, French B, Strom BL, et al. Race and sex differences in response to endothelin receptor antagonists for pulmonary arterial hypertension. Chest 2012; 141: 20-26.

28 Machado RD, Eickelberg O, Elliot CG, et al. Genetics and genomics of pulmonary arterial hypertension. J Am Coll Cardiol 2009; 54: S32-S42.

29 Austin ED, Hamid R, Hemnes AR, et al. BMPR2 expression is suppressed by signaling through the estrogen receptor. Biol Sex Differ 2012; 3: 6.

30 Austin ED, Cogan JD, West JD, et al. Alterations in oestrogen metabolism: implications for higher penetrance of familial pulmonary arterial hypertension in females. Eur Respir J 2009; 34: 1093-1099.

31 Roberts KE, Fallon MB, Krowka MJ, et al. Genetic risk factors for portopulmonary hypertension in patients with advanced liver disease. Am J Respir Crit Care Med 2009; 179: 835-842.

32 McLaughlin VV, Suissa S. Prognosis of pulmonary arterial hypertension: the power of clinical registries of rare diseases. Circulation 2010; 122: 106-108.

33 Wacholder S, McLaughlin JK, Silverman DT, et al. Selection of controls in case-control studies. I. Principles. Am J Epidemiol 1992; 135: 1019-1028.

34 Helzlsouer KJ, VDPP Steering Committee. Overview of the cohort consortium vitamin $\mathrm{D}$ pooling project of rarer cancers. Am J Epidemiol 2010; 172: 4-9.

35 Hörig H, Marincola E, Marincola FM. Obstacles and opportunities in translational research. Nat Med 2005; 11: 705-708.

36 Khoury MJ, Gwinn M, Ioannidis JP. The emergence of translational epidemiology: from scientific discovery to population health impact. Am J Epidemiol 2010; 172: 517-524. 